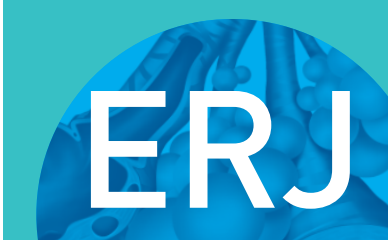

open research
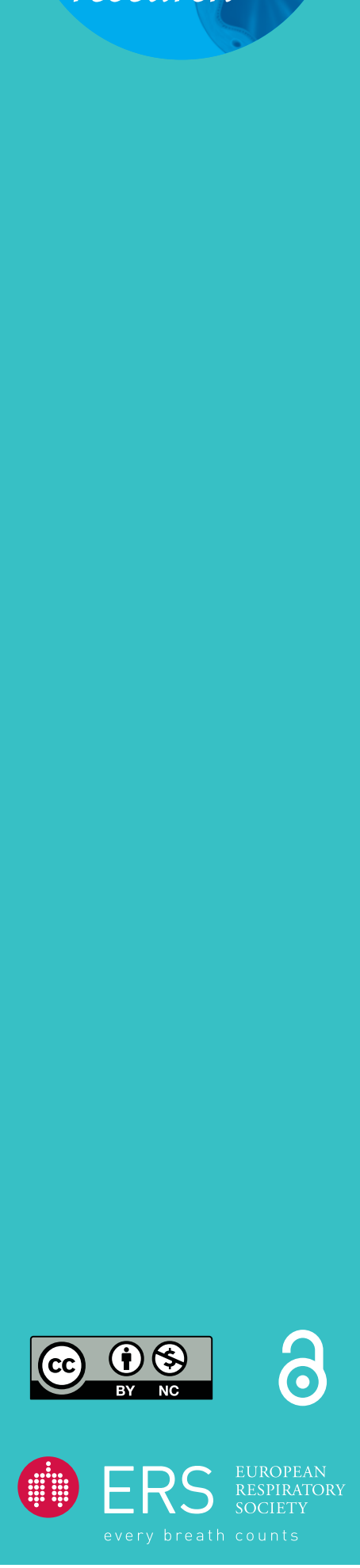

\title{
Ventilating two patients with one ventilator: technical setup and laboratory testing
}

\section{To the Editor:}

During health crises, including terrorist attacks or pandemics like coronavirus disease 2019 (COVID-19), the number of mechanical ventilators might fall short of the number of patients with severe respiratory failure [1-3]. A possible emergency solution is to ventilate multiple patients with one ventilator. Sharing ventilators was applied anecdotally during the 2017 Las Vegas (USA) shootings and has raised interest in lay media with the current COVID-19 pandemic [4]. However, ventilating two patients with one ventilator can be dangerous when incorrectly applied. Different setups have been published online, but none have reported any technical safety testing.

Technically, two ventilator circuits can be connected in parallel to one ventilator by adding T-connectors to the inspiratory and expiratory limbs. This was first reported using a setup to ventilate four test lungs, but very limited measurements were presented [5]. Another study demonstrated that ventilating four sheep with one ventilator was feasible for $12 \mathrm{~h}$ with frequent blood gases and repositioning [6]. In a more detailed laboratory evaluation, it was concluded that a single ventilator to support four patients is possible, but that tidal volume $\left(V_{\mathrm{T}}\right)$ cannot be controlled for each subject and depends on respiratory compliance [7]. To what extent different lung compliances affect $V_{\mathrm{T}}$ distribution was not described, nor the strategies to control $V_{\mathrm{T}}$ individually.

The aim of the current study was to design an improved setup to ventilate two patients with one ventilator and evaluate $V_{\mathrm{T}}$ distribution at different lung compliances. Furthermore, we aimed to individualise $V_{\mathrm{T}}$ by adding inspiratory resistances $\left(R_{\text {insp }}\right)$ in the circuit.

\section{Methods}

Two breathing circuits (RT380; Fisher \& Paykel, Auckland, New Zealand) were connected in parallel to a mechanical ventilator (Evita Infinity V500; Dräger, Lubeck, Germany) by T-connectors with one-way valves (\#1954000; Intersurgical, Wokingham, UK) to the inspiratory and expiratory ventilator limbs (figure 1a). The Y-piece of both breathing circuits were connected to a single port of the Dual Adult Lung simulator (Michigan Instruments, Grand Rapids, MI, USA) with calibrated pneumotachographs (Vyntus; Vyaire Medical, Mettawa, IL, USA) and HEPA filters positioned between Y-piece and the test lung.

Multiple experimental conditions were tested in pressure control (PC) mode (inspiratory time:expiratory time ratio 1:2, positive end-expiratory pressure (PEEP) $12 \mathrm{cmH}_{2} \mathrm{O}$, inspiratory rise time $0.1 \mathrm{~s}$ ). First, compliance of both test lungs $\left(C_{\text {lung }}\right)$ was gradually increased $\left(10-70 \mathrm{~mL} \cdot \mathrm{cmH}_{2} \mathrm{O}^{-1}\right)$ at an inspiratory peak pressure $\left(P_{\text {peak }}\right)$ of $22 \mathrm{cmH}_{2} \mathrm{O}$ at 25 breaths per min and thereafter 15 breaths per min. Second, $C_{\text {lung,right }}$ was gradually increased while $C_{\text {lung,left }}$ was fixed at $50 \mathrm{~mL} \cdot \mathrm{cmH}_{2} \mathrm{O}^{-1}$. Third, three levels of $R_{\text {insp }}$ were added to the right test lung by compressing the tube with an adjustable clamp, while no $R_{\text {insp }}$ was added to the left test lung. $C_{\text {lung }}$ was equal in both test lungs $\left(50 \mathrm{~mL} \cdot \mathrm{cmH}_{2} \mathrm{O}^{-1}\right)$ and $P_{\text {peak }}$ was set at $30 \mathrm{cmH}_{2} \mathrm{O}$ at 15 breaths per min. This experiment was repeated with $C_{\text {lung,right }}$ at $70 \mathrm{~mL} \cdot \mathrm{cmH}_{2} \mathrm{O}^{-1}$ and $C_{\text {lung,left }}$ at $20 \mathrm{~mL} \cdot \mathrm{cmH}_{2} \mathrm{O}^{-1}$. Finally, we simulated coughing by manual compression of one test lung in a setup with

@ERSpublications

With a modified circuit, it is feasible to ventilate two patients with one ventilator over a relevant range of compliances. Adding inspiratory resistance allows individual titration of tidal volume, and incorporating one-way valves prevents pendelluft. https://bit.ly/3ex8SYP

Cite this article as: de Jongh FHC, de Vries HJ, Warnaar RSP, et al. Ventilating two patients with one ventilator: technical setup and laboratory testing. ERJ Open Res 2020; 6: 00256-2020 [https:// doi.org/10.1183/23120541.00256-2020]. 
a)

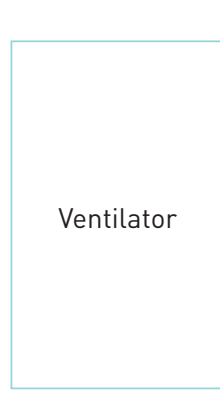

Inspiratory T-piece

port

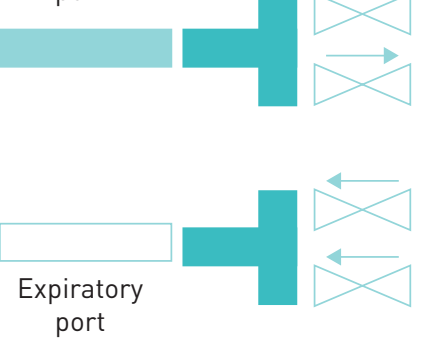

One-way

valve
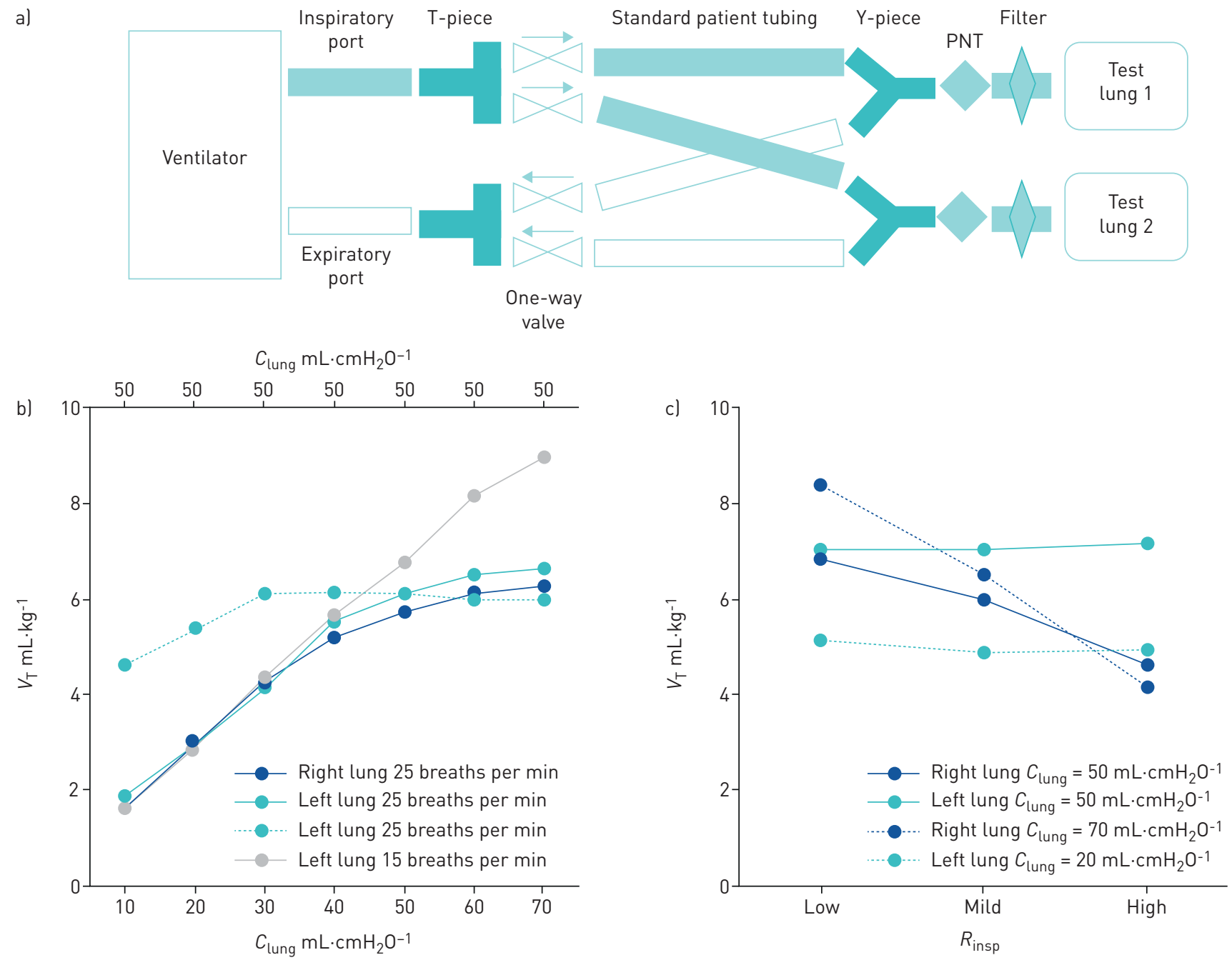

FIGURE 1 a) Experimental setup to connect two patients to one ventilator. Note that the one-way valves in the T-pieces we used were adapted to provide airflow in the shown directions. In our setup, we used a pneumotachograph (PNT) to record separate tidal volumes $\left(V_{T}\right)$ and airway opening pressures. In clinical practice, a capnograph or pressure port could also be used to facilitate individual patient monitoring. b) $V_{T}$ distribution between the right and left test lung (blue and green solid lines) at increasing test lung compliance ( $\mathcal{C}_{\text {lung, }}$, lower $\mathrm{x}$-axis) at 25 breaths per min and for the left test lung at 15 breaths per min (grey line). The dashed green line represents $V_{T}$ of the left test lung when $C_{\text {lung.left }}$ is kept constant (upper $\mathrm{x}$-axis), while $C_{\text {lung,right }}$ is gradually increased (blue solid line, lower $\mathrm{x}$-axis). Note that at very low $C_{\text {lung,right }}\left(10-20 \mathrm{~mL} \cdot \mathrm{cmH}_{2} \mathrm{O}^{-1}\right.$ ),

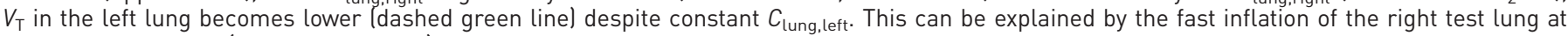
very low compliance (low time constant), which causes the ventilator to drastically decrease inspiratory flow and thereby averts complete inflation of the left test lung. $c)$ Effect of adding inspiratory resistance $\left(R_{\text {insp }}\right)$ to the right test lung (blue lines). No resistance was added to the left lung. Solid lines represent $V_{T}$ at equal test lung compliances $\left(50 \mathrm{~mL} \cdot \mathrm{cmH}_{2} \mathrm{O}^{-1}\right)$. Dashed lines represent $V_{T}$ at unequal test lung compliances ( $C_{\text {lung, right }}=70 \mathrm{~mL} \cdot \mathrm{cmH}_{2} \mathrm{O}^{-1}, C_{\text {lung,left }}=20 \mathrm{~mL} \cdot \mathrm{cmH}_{2} \mathrm{O}^{-1}$ ).

and without one-way valves. Measurements for each experimental condition were performed for $1 \mathrm{~min}$. $V_{\mathrm{T}}$ to each test lung was calculated as an average over all breaths. $V_{\mathrm{T}}$ is expressed in $\mathrm{mL} \cdot \mathrm{kg}^{-1}$ considering a patient with a predicted bodyweight of $80 \mathrm{~kg}$.

\section{Results}

Figure $1 \mathrm{~b}$ shows that $V_{\mathrm{T}}$ in both test lungs remain comparable when $C_{\text {lung }}$ is gradually increased at 25 breaths per min. Due to the longer respiratory time constant at higher compliance and the short inspiratory time there is a deflection in the $V_{\mathrm{T}}$ curve, which becomes linear at 15 breaths per min. Increasing $C_{\text {lung,right }}$ while keeping $C_{\text {lung,left }}$ constant results in a constant $V_{\mathrm{T}}$ in the left lung, except for very low compliances. Figure $1 \mathrm{c}$ shows that adding resistance to the inspiratory limb of the right test lung decreases $V_{\mathrm{T}}$, while $V_{\mathrm{T}}$ in the left test lung remains constant.

In a setup without one-way valves, peak cough pressure, simulated by manual compression of the left test lung, was transmitted to the right test lung (both $10 \mathrm{cmH}_{2} \mathrm{O}$ ) and $68 \%$ of cough volume $(190 \mathrm{~mL}$ ) was inspired by the right test lung. Adding one-way valves to the setup completely prevented this pendelluft effect. 
On average, we found that $V_{\mathrm{T}}$ measured by the ventilator was $5 \%$ higher than the sum of the $V_{\mathrm{T}}$ delivered to both test lungs (measured using the pneumotachographs).

Experiments were repeated with other intensive care unit ventilators (Getinge Servo-U/Servo-I, Getinge, Mansfield, UK; Philips Respironics V680, Philips, Guildford, UK; Hamilton Medical G5 and G6, Hamilton Medical, Bonaduz, Switzerland) as well as another breathing circuit (\#2000000S, Intersurgical, Wokingham, UK), and provided similar results.

\section{Discussion}

The major finding of the current bench study is that with a modified ventilator circuit it is technically feasible to ventilate two patients with one ventilator over a clinically relevant range of compliances in PC mode. Second, adding $R_{\text {insp }}$ allows individual titration of $V_{\mathrm{T}}$. Third, incorporating one-way valves in the circuit improves safety of the setup by preventing pendelluft.

In agreement with a previous study, $V_{\mathrm{T}}$ was distributed evenly between test lungs with a similar compliance [6]. In addition, we tested this over a large range of clinically relevant compliances and found that if compliance changes in one test lung, $V_{\mathrm{T}}$ is preserved in the other test lung (except at very low compliance). In other words, changes in respiratory mechanics in one patient will not affect the other patient. This is of clinical relevance because respiratory mechanics in critically ill patients are subject to constant change or differ due to anthropometric differences. Importantly, our findings only apply to PC mode. In volume control mode, changes in respiratory mechanics in one patient, or worse a complete airway obstruction, will distribute $V_{\mathrm{T}}$ to the other patient.

By adding $R_{\text {insp }}$ (i.e. increasing the respiratory time constant) to one test lung, we were able to control $V_{\mathrm{T}}$. As shown in figure $1 c$, this may facilitate ventilating two patients with different respiratory mechanics with the same protective $V_{\mathrm{T}}$. Note that this only applies when flow does not reach zero at end-inspiration and requires careful monitoring of $V_{\mathrm{T}}$.

In contrast to other studies [5-7], we added one-way valves to the circuit to prevent backflow between patients for two reasons. First, to avoid high pressures, for instance with coughing or airway suctioning, being transmitted to the other patient. Expiratory pressure with coughing may exceed $100 \mathrm{cmH} 2 \mathrm{O}$. Second, to limit infectious cross-contamination, although this requires further studies.

Recently, multiple professional societies in the USA issued a consensus statement with multiple reasons for avoiding ventilating multiple patients with one ventilator [8]. Many of these reasons apply to volume control modes, which, as discussed here, should be avoided. Furthermore, adding additional $R_{\text {insp }}$ and one-way valves to the circuit as in our setup allows partial individualisation and prevents pendelluft. Nevertheless, several important practical considerations remain. First, patient breathing effort in PC mode should be absent or ventilator triggering disabled, as triggering by one patient will result in severe patient-ventilator asynchrony for the other patient. This approach is therefore not applicable during weaning. Second, respiratory rate, I:E ratio, inspiratory oxygen fraction and PEEP cannot be individualised. Third, individual monitoring is required and ideally includes capnography, flow and inspiratory pressure near the endotracheal tube, and pulse oximetry. Fourth, alarm settings of $V_{\mathrm{T}}$ should be adapted to multiple patients. Stringent alarm limits on $V_{\mathrm{T}}$ may be used to monitor whether one of the patient's respiratory mechanics are changing. Finally, we would like to emphasise that our approach is off-label ventilator use and should only be considered in emergency situations, after ethical board approval, consultation of all stakeholders and adequate training.

Sharing ventilators between two patients may be a life-saving rescue intervention in health crisis or in low-resource countries. Future studies should be performed to improve this strategy and further develop clinical safety testing.

Frans H.C. de Jongh ${ }^{1,2,3,9}$, Heder J. de Vries ${ }^{4,5,9}$, Rob S.P. Warnaar ${ }^{6}$, Eline Oppersma ${ }^{6}$, Rudolf Verdaasdonk ${ }^{7}$, Leo M.A. Heunks ${ }^{4,5}$ and Jonne Doorduin $\circledast^{8}$

${ }^{1}$ Dept of Pulmonology, Medisch Spectrum Twente, Enschede, The Netherlands. ${ }^{2}$ TechMed Centre, University of Twente, Enschede, The Netherlands. ${ }^{3}$ Dept of Neonatal Intensive Care Medicine, Amsterdam UMC, Amsterdam, The Netherlands. ${ }^{4}$ Dept of Intensive Care Medicine, Amsterdam UMC, Amsterdam, The Netherlands. ${ }^{5}$ Amsterdam Cardiovascular Sciences Research Institute, Amsterdam UMC, Amsterdam, The Netherlands. ${ }^{6}$ Cardiovascular and Respiratory Physiology, TechMed Centre, University of Twente, Enschede, The Netherlands. ${ }^{7}$ Health Technology Implementation, TechMed Centre, University of Twente, Enschede, The Netherlands. ${ }^{8}$ Dept of Neurology, Donders Institute for Brain, Cognition and Behaviour, Radboud University Medical Center, Nijmegen, The Netherlands. ${ }^{9}$ These authors contributed equally. 
Correspondence: Jonne Doorduin, Radboud University Medical Center, Reinier Postlaan 4, 6525 GC, Nijmegen, The Netherlands. E-mail: jonne.doorduin@radboudumc.nl

Received: 8 May 2020 | Accepted: 18 May 2020

Author contributions: F.H.C. de Jongh, H.J. de Vries, L.M.A. Heunks, R. Verdaasdonk and J. Doorduin conceived and designed the study; F.H.C. de Jongh, H.J. de Vries, R.S.P. Warnaar, R. Verdaasdonk and J. Doorduin acquired the data; F.H.C. de Jongh, R.S.P. Warnaar and J. Doorduin analysed the data; F.H.C. de Jongh, H.J. de Vries, R.S.P. Warnaar, E. Oppersma, L.M.A. Heunks, R. Verdaasdonk and J. Doorduin interpreted the data; and F.H.C. de Jongh, H.J. de Vries, R.S.P. Warnaar, E. Oppersma, L.M.A. Heunks, R. Verdaasdonk and J. Doorduin drafted and revised the manuscript.

Conflict of interest: F.H.C. de Jongh has nothing to disclose. H.J. de Vries has nothing to disclose. R.S.P. Warnaar has nothing to disclose. E. Oppersma has nothing to disclose. R. Verdaasdonk has nothing to disclose. L.M.A. Heunks reports a grant from ZonMw (CVID technology grant from Dutch goverment) during the conduct of the study; and a grant from Liberate Medical for expiratory muscle research and a grant from Orion Pharma for a levosimendan study, outside the submitted work. J. Doorduin has nothing to disclose.

Support statement: This study was supported by a grant from "ZonMw program Creative solutions CoVID-19" (number 5000.9953). Funding information for this article has been deposited with the Crossref Funder Registry.

\section{References}

1 Rubinson L, Branson RD, Pesik N, et al. Positive-pressure ventilation equipment for mass casualty respiratory failure. Biosecur Bioterror 2006; 4: 183-194.

2 Rubinson L, Nuzzo JB, Talmor DS, et al. Augmentation of hospital critical care capacity after bioterrorist attacks or epidemics: recommendations of the Working Group on Emergency Mass Critical Care. Crit Care Med 2005; 33: 2393-2403.

3 Rubinson L, O’Toole T. Critical care during epidemics. Crit Care 2005; 9: 311-313.

4 Rosenthali BM, Pinkowski J, Goldstein J. 'The Other Option Is Death': New York Starts Sharing of Ventilators. New York, The New York Times, 2020.

5 Neyman G, Irvin CB. A single ventilator for multiple simulated patients to meet disaster surge. Acad Emerg Med 2006; 13: 1246-1249.

6 Paladino L, Silverberg M, Charchaflieh JG, et al. Increasing ventilator surge capacity in disasters: ventilation of four adult-human-sized sheep on a single ventilator with a modified circuit. Resuscitation 2008; 77: 121-126.

7 Branson $\mathrm{RD}$, Blakeman $\mathrm{TC}$, Robinson $\mathrm{BR}$, et al. Use of a single ventilator to support 4 patients: laboratory evaluation of a limited concept. Respir Care 2012; 57: 399-403.

8 American Society of Anesthesiologists. Joint statement on multiple patients per ventilator. https://www.asahq.org/ about-asa/newsroom/news-releases/2020/03/joint-statement-on-multiple-patients-per-ventilator Date last updated: 26 March 2020. Date last accessed: 18 June 2020. 